Related content

Chemical Erosion Behaviour of Doped Graphites under Hydrogen Impact: A Comparison of lon Beam Experiments and Planar Inductively Coupled RF Plasmas

To cite this article: M Balden et al 2004 Phys. Scr. 2004123

\author{
- Erosion Processes of Carbon Materials \\ under Hydrogen Bombardment and their \\ Mitigation by Doping \\ E de Juan Pardo, M Balden, B Cieciwa et \\ al. \\ Deuterium Retention by Implantation in \\ Carbide-Doped Graphites \\ M Balden, E Oyarzabal, E de Juan Pardo \\ et al. \\ - Erosion of Carbon in Dual-Beam \\ Experiments: an Overview \\ A A Haasz and J W Davis
}

View the article online for updates and enhancements. 


\title{
Chemical Erosion Behaviour of Doped Graphites under Hydrogen Impact: A Comparison of Ion Beam Experiments and Planar Inductively Coupled RF Plasmas
}

\author{
M. Balden ${ }^{1, *}$, E. de Juan Pardo ${ }^{1}$, H. Maier ${ }^{1}$, P. Starke ${ }^{1,2}$ and U. Fantz ${ }^{\mathrm{b}}$ \\ ${ }^{1}$ Max-Planck-Institut für Plasmaphysik, EURATOM Association, Boltzmannstr. 2, D-85748 Garching, Germany \\ ${ }^{2}$ Lehrstuhl für Experimentelle Plasmaphysik, Institut für Physik, Universität Augsburg, D-86135 Augsburg, Germany
}

Received October 1, 2003; accepted December 17, 2003

PACS Ref: 28.52 . Fa, 79.20.Rf, 52.25.Ya, 52.40.Hf, 52.70.Nc, 68.37.Hk, 81.05.Uw, 82.80.Ms

\begin{abstract}
Carbide-doped and pure graphites were eroded by energy- and mass-separated hydrogen ion beams and by hydrogen containing planar inductively coupled $\mathrm{RF}$ plasmas. The erosion yield for $30 \mathrm{eV} \mathrm{D}$ impact on doped graphites and its fluence dependence are in the same order of magnitude for both exposure types. The D flux from the plasma onto the specimens $\left(\sim 3.1 \times 10^{21} \mathrm{~m}^{-2} \mathrm{~s}^{-1}\right)$ contains energetic $\mathrm{D}$ ions and thermal $\mathrm{D}(650 \mathrm{~K})$ in the ratio 1 to 5 . The contribution of the thermal $\mathrm{D}$ to the erosion yield reaches at most the same magnitude as the erosion yield by ions only $(30 \mathrm{eV})$. This contribution depends on the structure of the graphite. In the case of pure graphites the observed erosion yield is independent of the fluence for both types of exposure, although a rough surface morphology is created. For doped graphites reductions of the erosion yield with fluence by a factor of about 10 are observed, while the surfaces get rough and strongly enriched with dopants.
\end{abstract}

\section{Introduction}

Carbon-based materials are considered as plasma-facing material (PFM) for fusion plasma devices [1,2]. The erosion yield of carbon by energetic hydrogen of several percent (chemical erosion) [3-10] together with the ability of carbon to trap large quantities of hydrogen (up to $\mathrm{H} / \mathrm{C} \approx 1)[11,12]$ in re-deposited layers will lead to low component lifetime [1] and to high in-vessel tritium inventories [12]. Together with the degradation of the mechanical properties due to neutron irradiation, these are the main disadvantages of carbon usage in future fusion devices. The particle and energy loads to the PFM are characterised by a broad variety of particle, energy, and angle distributions. As input data for simulations of the plasma-wall interaction [13-15], erosion yields from ion beam experiments are used. In the case of carbon this has to be done with care, because its chemical erosion by thermal atomic hydrogen has a synergetic effect with simultaneously impacting energetic ion beams. This behaviour was reported in earlier and recent studies [16,17] and reviewed in [4]. Impact of thermal hydrogen results in an erosion yield two orders of magnitude lower than with simultaneous bombardment by atomic hydrogen and low energy ions (ion energy $>$ several eV) [4]. Therefore, simple superposition of erosion yields, which is correct for pure physical sputtering, does not describe the behaviour of carbon-based materials under simultaneous thermal (atomic) and energetic (ionic) hydrogen impact. In this paper the yields observed from ion beam experiments and

\footnotetext{
*e-mail: martin.balden@ipp.mpg.de
}

from a well characterised plasma with a high content of thermal atomic hydrogen are compared to evaluate the contribution of thermal D to the synergetic effect with energetic D.

Doping of the carbon material is a possibility to mitigate the strong erosion $[4,5,18]$. The erosion behaviour of doped carbon was extensively studied using ion beams [6,18-23], while it was rarely investigated under plasma exposure (with sufficient characterisation of the particle fluxes) [24-26]. In this paper the first erosion data obtained by exposing doped graphites to planar inductively coupled RF plasmas are presented and compared with published data from ion beam experiments [19,27].

\section{Experimental}

\subsection{Materials and specimens}

The materials used in this study are pure and carbidedoped graphites from different producers. The names and some properties of these materials are listed in Table I $[20,28,29]$. The erosion behaviour of some of these materials were already investigated [3,7,19,20,27].

Small plates with $2-11 \mathrm{~cm}^{2}$ upper surface were used as specimens. The surfaces were polished except for the $\mathrm{C} / \mathrm{SiC}$ specimen (Table I), which was only cut. After polishing, the specimens were cleaned in an ultrasonic bath. Due to the polishing the dopant grains were depleted in the surface near layer of $\sim 1 \mu \mathrm{m}$ thickness [19,28].

The specimens were usually weighed before and after erosion measurements by ion beam or by plasma exposure. From the mass loss and the determined deuterium (hydrogen) fluence onto the specimen, the total erosion yield (eroded C atoms/impacting D atoms) was obtained.

\subsection{Ion beam experiments}

An ion source with a mass and energy selecting magnet system (high current ion source at IPP Garching [8]) was adjusted to produce a $90 \mathrm{eV} \mathrm{D}_{3}^{+}$ion beam, i.e. $30 \mathrm{eV}$ per $\mathrm{D}$, with a flux of $\sim 10^{19} \mathrm{~m}^{-2} \mathrm{~s}^{-1}$. The size of the erosion spot was $\sim 0.8 \mathrm{~cm}^{2}$ for this impact energy. The specimens were weighed with a micro-balance in vacuo. The balance has an accuracy of $1 \mu \mathrm{g}$. The weight loss was determined sequentially at various fluences to obtain the fluence dependence of the total carbon erosion yield, i.e. the physical and chemical part. This yield was calculated by assuming that the whole weight loss is due to carbon 
Table I. Names and some properties of the specimen materials (Note: * the dopant is depleted in the surface, ** $M C M B=$ meso-carbon micro-beads, *** with large WC grain clusters, i.e. a strongly inhomogeneous dopant distribution).

\begin{tabular}{|c|c|c|c|c|c|}
\hline Name & Short description & $\begin{array}{l}\text { Density } \\
\left(\mathrm{g} / \mathrm{cm}^{3}\right)\end{array}$ & $\begin{array}{l}\text { Bulk composition }{ }^{*} \\
\text { (at. } \% \text { of dopant) }\end{array}$ & $\begin{array}{l}\text { Main grain size } \\
\text { of dopant }(\mu \mathrm{m})\end{array}$ & Producer \\
\hline HPG & $\begin{array}{l}\text { Pyrolytic graphite with } \\
\text { mosaic spread of } \sim 30^{\circ} \\
\text { cut parallel to main } \\
\text { basal plane orientation } \\
\text { (Grade HPG) }\end{array}$ & 2.24 & Non & - & Union Carbide, USA \\
\hline EK98 & Fine-grain graphite & 1.86 & Non & - & SGL Carbon AG, Germany \\
\hline $\mathrm{R} 6650 \mathrm{M}$ & Fine-grain graphite & 1.85 & Non & - & SGL Carbon AG, Germany [30] \\
\hline $\mathrm{C}_{\mathrm{CEIT}}$ & $\begin{array}{l}\text { Graphitised by heating } \\
\text { of } \mathrm{MCMB}^{* *}\end{array}$ & $\sim 1.9$ & Non & - & CEIT, San Sebastian, Spain $[28,29]$ \\
\hline $\mathrm{TiC} 2$ & $\begin{array}{l}\text { Graphitised by heating } \\
\text { of } \mathrm{MCMB}^{* *} \text { mixed with } \\
\text { carbide powder } \\
\left(\mathrm{TiC}, \mathrm{VC}, \mathrm{WC}, \mathrm{Zr}_{7} \mathrm{C}_{8}\right)\end{array}$ & - & 2 at. $\% \mathrm{Ti}$ & $\sim 1$ & CEIT, San Sebastian, Spain $[28,29]$ \\
\hline $\mathrm{TiC} 4$ & see $\mathrm{TiC} 2$ & $\sim 2.1$ & 4 at. $\% \mathrm{Ti}$ & $\sim 1$ & see $\mathrm{TiC} 2$ \\
\hline VC4 & see $\mathrm{TiC} 2$ & $\sim 2.0$ & 4 at. $\% \mathrm{~V}$ & $0.9-1.3$ & see $\mathrm{TiC} 2$ \\
\hline WC4 & see $\mathrm{TiC} 2$ & $\sim 2.9$ & 4 at. $\% \mathrm{~W}$ & $\sim 0.7$ & see $\mathrm{TiC} 2$ \\
\hline WC4in & see $\mathrm{TiC} 2$ & $\sim 2.9$ & 4 at. $\% \mathrm{~W}$ & $\sim 0.7^{* * *}$ & see $\mathrm{TiC} 2$ \\
\hline $\mathrm{ZrC4}$ & see $\mathrm{TiC} 2$ & $\sim 2.3$ & 4 at. $\% \mathrm{Zr}$ & $\sim 1$ & see $\mathrm{TiC} 2$ \\
\hline RGTi91 & $\begin{array}{l}\text { Uniaxial pressing of a } \\
\text { mixture of graphite and } \\
\text { Ti powders and } \\
\text { re-crystallisation with } \\
\text { TiC formation }\end{array}$ & 2.23 & 2 at. $\% \mathrm{Ti}$ & $\sim 2-5$ & $\begin{array}{l}\text { Composite, Moscow, } \\
\text { Russia via Efremov Institute, } \\
\text { St. Petersburg, Russia [20] }\end{array}$ \\
\hline LT10 & $\begin{array}{l}\text { Isostatic pressed } \\
\text { graphite and } \mathrm{TiC} \\
\text { powder mixture }\end{array}$ & 2.79 & 10 at. $\% \mathrm{Ti}$ & $\sim 2-5$ & CERAM, France \\
\hline $\mathrm{C} / \mathrm{SiC}$ & $\begin{array}{l}2 \mathrm{D} \text { carbon fibre } \\
\text { architecture with } \mathrm{SiC} \\
\text { matrix }\end{array}$ & - & $\sim 20$ at. $\% \mathrm{Si}$ & - & MAN Technologie AG, Germany \\
\hline
\end{tabular}

erosion, thus neglecting any dopant loss. For all carbides used as dopants, the threshold for physical sputtering is above $30 \mathrm{eV}$ [8]. (Please notice that $\mathrm{SiC}$ and $\mathrm{Si}$ have a low chemical erosion [30].) Therefore, the dopant loss could only occur as loss of whole dopant grains which would only increases the erosion yield as a systematic error.

An increase of the temperature of the specimen by $30 \mathrm{eV}$ ion impact was negligible. The specimen could be heated up to a desired temperature of maximal $\sim 1400 \mathrm{~K}$ with electron bombardment from the rear.

\subsection{Planar inductively coupled RF plasma}

A plasma was ignited in a mixture of $\mathrm{D}_{2}\left(\mathrm{H}_{2}\right)$ and $\mathrm{He}$ gas in the ratio 1 to 10 at a total pressure of $20 \mathrm{~Pa}$ in a small vacuum chamber ( $\sim 2$ litres volume). The purpose of the $\mathrm{He}$ is to maximise the atomic and ionic hydrogen flux onto the specimen (and to alter the ion composition). A radio frequency (RF) power of $250 \mathrm{~W}$ was inductively coupled into the plasma with a planar coil $\left(f_{\mathrm{RF}}=27.12 \mathrm{MHz}\right)$. The impacting particle flux onto the specimen consisted of thermal atomic $\mathrm{D}(\mathrm{H})$ and ions (beside the $\mathrm{D}_{2}\left(\mathrm{H}_{2}\right)$ and $\mathrm{He}$ gas). By spatially resolved optical emission spectroscopy the thermal atomic D $(\mathrm{H})$ flux was determined to be $2.6 \pm 0.3 \times 10^{21} \mathrm{~m}^{-2} \mathrm{~s}^{-1}$. The energy of the atomic $\mathrm{D}$ was equivalent to the plasma temperature of $\sim 650 \mathrm{~K}$ $(\sim 0.06 \mathrm{eV})$. The ionic part of the impacting particle flux (also of $\mathrm{He}$ ) was investigated with an energy-resolved mass spectrometer and its flux was determined to be $5.2 \pm 0.5 \times 10^{20} \mathrm{~m}^{-2} \mathrm{~s}^{-1}$, i.e. a flux ratio of thermal to energetic D of 1 to 5 [31-33]. The ions gained an energy of (usually) $30 \mathrm{eV}$ by biasing the specimen. The majority of the ions were $\mathrm{D}^{+}$, while $\mathrm{D}_{3}^{+}(10 \mathrm{eV}$ per $\mathrm{D})$ and $\mathrm{D}_{2}^{+}(15 \mathrm{eV}$ per D) were a factor of 3-5 less. The ratio of impacting $\mathrm{He}$ ions to $\mathrm{D}$ ions was below $10^{-2}$, which is explainable by the difference of the ionisation energy of hydrogen $(13.6 \mathrm{eV})$ and helium $(24.6 \mathrm{eV})$. Due to this ratio, effects of He on the chemical erosion were neglected. All fluences were determined by multiplying these fluxes with the exposure time.

The specimen holder was actively cooled to achieve $\sim 300 \mathrm{~K}$, which was the temperature chosen for most experiments. Without cooling the specimen heated up to about $500 \mathrm{~K}$.

The carbon erosion yield was determined from the spectroscopically measured time-resolved $\mathrm{D}_{\gamma}$-line and CDand $\mathrm{C}_{2}$-bands, which monitor the $\mathrm{D}, \mathrm{CD}_{x}$, and $\mathrm{C}_{2} \mathrm{D}_{y}$ flux, respectively. The time evolution describes the fluence dependence of the chemical erosion in relative units. At the beginning of the plasma exposure all plasma and wall parameters had to come to equilibrium. During that stabilisation phase of about half an hour, meaningful erosion data could not be obtained and a non-quantifiable deviation from the calculated fluence appeared. The total erosion yield averaged over the applied fluence (Table II) was determined by weighing the specimens before and after the plasma exposure outside the vacuum chamber and attributing the whole weight loss to carbon erosion (see Section 2.2). These mass loss data were also used to scale the spectroscopic signals to carbon erosion yields. More 
Table II. Total carbon erosion yields $\left(\mathrm{Y}_{t+e}, \mathrm{Y}_{e}\right)$ for different specimens obtained from the plasma experiment by weight loss measurements. Erosion yields by $H$ plasmas are given in parentheses. The erosion yield $\mathrm{Y}_{i}$ at 300 and $500 \mathrm{~K}$ for $30 \mathrm{eV} \mathrm{D}$ ion impact are 3-4\% and 4\%, respectively [3].

\begin{tabular}{lllll}
\hline Name & $\begin{array}{l}\text { Ion energy } \\
(\mathrm{eV})\end{array}$ & $\begin{array}{l}\text { Specimen temperature } \\
(\mathrm{K})\end{array}$ & $\begin{array}{l}\text { Erosion yield } Y_{\mathrm{t}+\mathrm{e}} \\
(\mathrm{C} / \text { thermal +energetic D) }(\%)\end{array}$ & $\begin{array}{l}\text { Erosion yield } Y_{\mathrm{e}} \\
(\mathrm{C} / \mathrm{energetic} \mathrm{D)}(\%)\end{array}$ \\
\hline EK98 & 30 & 300 & $0.79(0.48$ for H) & $4.8(2.9$ for H) \\
R6650M & 30 & 300 & 0.95 & 5.7 \\
R6650M & 30 & 500 & 1.1 & 6.4 \\
HPG & 30 & 500 & 0.63 & 3.8 \\
C 6 IT & 30 & 500 & 1.3 & 7.9 \\
TiC4 & 15 & 300 & 0.33 & 2.0 \\
RGTi91 & 30 & 300 & $0.76(0.58$ for H) & $4.5(3.5$ for H) \\
C/SiC & 30 & 300 & 0.44 & 2.7 \\
VC4 & 30 & 500 & 1.3 & 7.9 \\
WC4 & 30 & 500 & 0.62 & 3.7 \\
WC4in & 30 & 300 & 3.6 & - \\
ZrC4 & 30 & 500 & 1.3 & 7.9 \\
\hline
\end{tabular}

details of the experimental set-up and the data analysis can be found in [31-33].

\subsection{Surface morphology characterisation and composition}

The surfaces of the specimens were investigated before and after the erosion experiments using a scanning electron microscope (SEM) (Phillips/FEI XL-30 ESEM) equipped with energy-dispersive X-ray spectroscopy (EDX). Due to the strong roughness, the material contrast of the backscattered electrons needed in certain cases assistance by EDX to distinguish between carbon and dopant grains.

Surface and bulk concentrations for the doped materials were obtained from backscattering of 0.8 and $4 \mathrm{MeV}{ }^{4} \mathrm{He}$ ion beams $[19,28]$.

\section{Results and discussion}

Figures 1 and 2 show a compilation of the erosion yield versus the D fluence for pure and doped graphites from ion beam experiments and plasma exposure, respectively. The previously published results [19] for the materials used in this study are also given in Fig. 1.

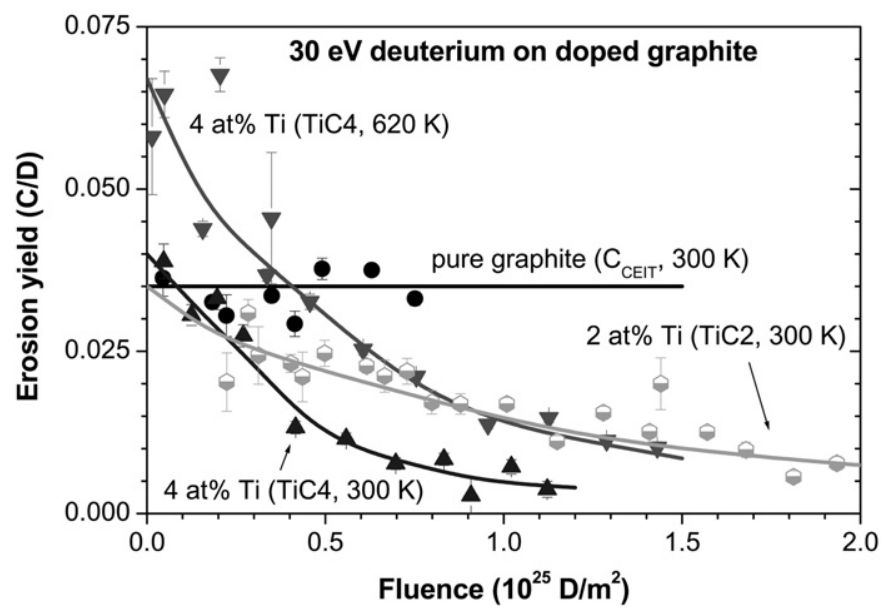

Fig. 1. Fluence dependence of the total erosion yield obtained at 300 and $620 \mathrm{~K}$ with a $30 \mathrm{eV} \mathrm{D}$ ion beam of the flux of the order of $10^{19} \mathrm{D} / \mathrm{m}^{2} \mathrm{~s}$. The lines are only to guide the eyes. For pure graphite the total erosion yield is $8-9 \%$ for $30 \mathrm{eV}$ at a temperature of $620 \mathrm{~K}$ [3].

\subsection{Erosion yield of pure graphites}

From ion beam experiments many erosion data are available for pure graphites [3-8]. The total erosion yield for $30 \mathrm{eV} \mathrm{D}$ impact at about room temperature ranges from 3 to $4 \%$. No systematic variation could be attributed to the type of carbon material, i.e. the microscopic carbon structure [3,7]. Also no fluence dependence of the erosion yield was observed [19]. Total erosion yields of $8-9 \%$ are reported for $30 \mathrm{eV}$ at temperatures of $620 \mathrm{~K}$, while it is only $\sim 4 \%$ at $500 \mathrm{~K}[3]$.

The total erosion yields of pure graphites obtained by weight loss after plasma exposure are given in Table II and for some specimens their evolution with D fluence is shown in Fig. 2. To evaluate the influence of the thermal D in presence of energetic D (synergetic effect), the erosion yield defined as eroded $\mathrm{C}$ atoms per incident thermal + energetic $\mathrm{D}$ atoms $\left(Y_{\mathrm{t}+\mathrm{e}}\right)$ and the yield defined as eroded $\mathrm{C}$ atoms per energetic D atoms only $\left(Y_{\mathrm{e}}\right)$ have to be considered (see Table II and axes of Fig. 2). $Y_{\mathrm{e}}$ has to be compared with the ion beam yield $Y_{\mathrm{i}}$, which is defined as eroded $\mathrm{C}$ atoms per energetic D atoms delivered from an ion beam without thermal atomic D flux.

For the fine-grain graphites $\left(\mathrm{C}_{\mathrm{CEIT}}\right.$ and $\mathrm{R} 6650 \mathrm{M}$, Table II), $Y_{\mathrm{e}}$ at $\sim 500 \mathrm{~K}$ is about 50 to $100 \%$ increased compared to $Y_{\mathrm{i}}(\sim 4 \%$ yield $)$. Thus, for the flux ratio of thermal to energetic D of 1 to 5 , the erosion yield is at most doubled due to the synergetic effect of simultaneous impact of thermal and energetic D. The reported flux dependence of the carbon erosion yield by hydrogen [9] can be neglected, because the D flux of $\sim 3 \times 10^{21} \mathrm{~m}^{-2} \mathrm{~s}^{-1}$ is just below the range where the yield starts to decrease.

For the pyrolytic graphite with the basal planes almost parallel to the surface, no increase of the erosion yield $Y_{\mathrm{e}}$ compared to $Y_{\mathrm{i}}$ was found. A significant variation of the erosion yield with the type of carbon material was observed at $\sim 500 \mathrm{~K}$ under $30 \mathrm{eV}$ ion impact, e.g. for $Y_{\mathrm{t}+\mathrm{e}}: \sim 1.2 \%$ and $0.63 \%$ for fine-grain graphites $\left(\mathrm{C}_{\mathrm{CEIT}}, \mathrm{R} 6650 \mathrm{M}\right)$ and pyrolytic graphite, respectively. These variations can be explained by the anisotropy of the erosion yield of the basal and prism plane of graphite [34] and by the amount of possible reaction sites (natural and ion-induced) for the thermal D in the materials. (It should be noted that the 


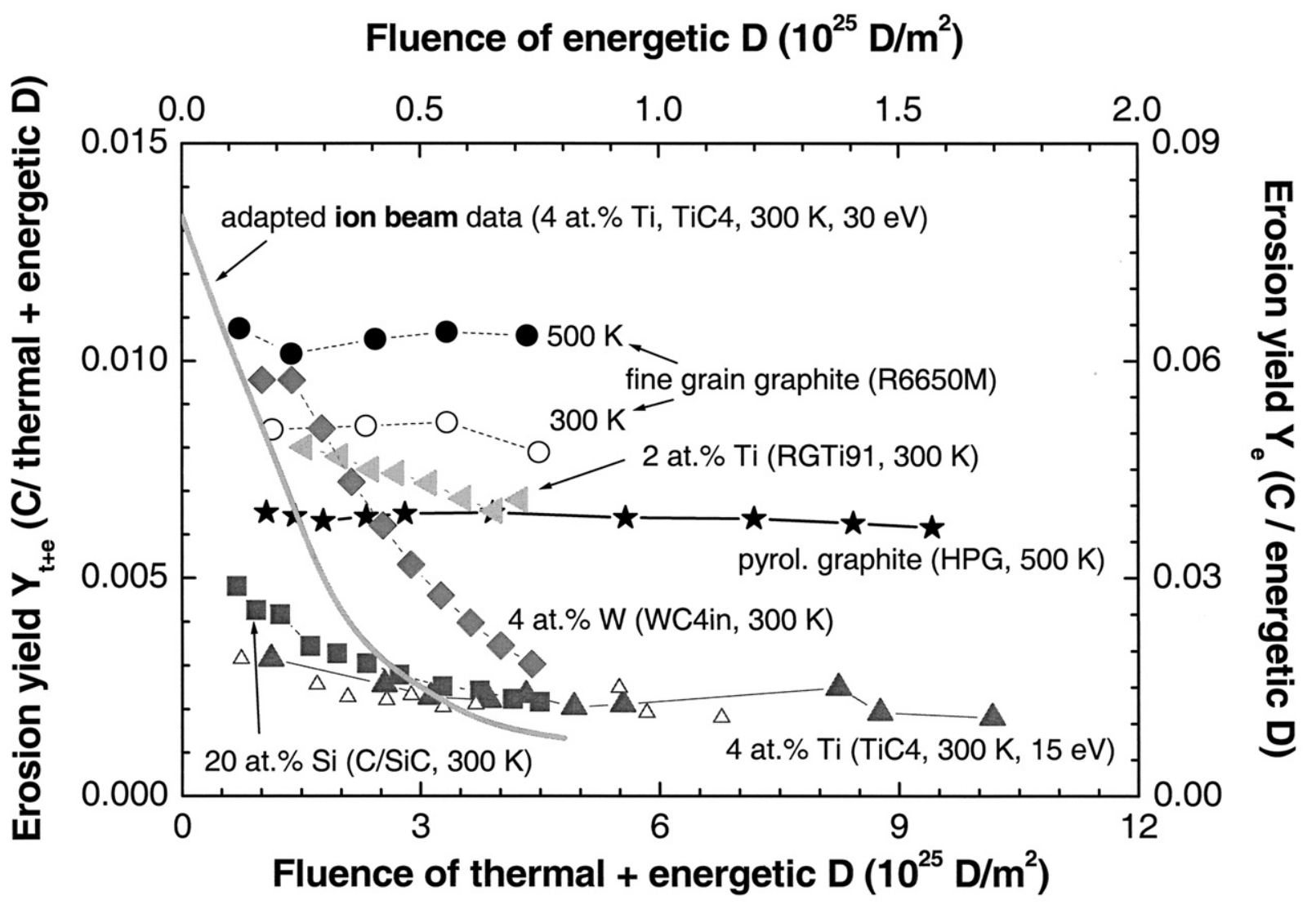

Fig. 2. Fluence dependence of the chemical erosion yield obtained by RF plasma exposure with $30 \mathrm{eV} \mathrm{D}$ impact. The erosion yield is given with respect to the energetic D fluence only (top and right axes) and with respect to the sum of thermal and energetic D fluence (bottom and left axes). For comparison the data of the TiC4 eroded at $15 \mathrm{eV} \mathrm{D}$ are re-scaled to $30 \mathrm{eV}$ (open triangles). The data of the TiC4 eroded with the ion beam are adapted to the thermal + energetic D impact (thick line). More details of the re-scaling can be found in the text.

maximum of the chemical erosion for plasma exposure was found at temperatures around $800 \mathrm{~K}$, while for ion beams it is already reached at $620 \mathrm{~K}$ due to the lower D flux used [10].)

For both, the fine-grain and the pyrolytic graphite, no fluence dependence of the erosion yield was observed.

The dependence on the specimen temperature (300$800 \mathrm{~K}$ ), ion energy (5-40 eV), and projectile type (D and H) were studied in detail by H. Paulin [31], but for the graphite EK98 only which is very similar to R6650M. It must be noted that the isotopic effect, i.e. the ratio of erosion yields of $\mathrm{D}$ and $\mathrm{H}$ at $\sim 300 \mathrm{~K}$ and with energies around $30 \mathrm{eV}$, is smaller for the plasma exposure $(1.6$; see $[31,32])$ compared to the ratio previously observed for ion beams only (5; see $[3,7])$. Results of another group, however, indicate a ratio of $\sim 2[6,35]$. The reasons for these differences are still unclear. It may be speculated that the synergetic effect reduces the isotopic effect. However, further investigations are needed.

\subsection{Erosion yield of doped graphites}

As in the case of pure carbon materials, many erosion data of doped graphites obtained with ion beams exist in the literature (see references in [6,18]). But high fluences were only accumulated under varying conditions (like specimen temperature and ion energy, i.e. history of specimen), even though the surface composition and morphology changes were investigated [19,22].

In Fig. 1 the fluence dependence of the total erosion yield by ion beams for Ti-doped graphites is shown for two fixed temperatures $(300$ and $620 \mathrm{~K}$ ) and with $30 \mathrm{eV}$ ion energy.
The fastest and strongest reduction by a factor of $\sim 10$ is observed for 4 at. $\%$ Ti-doped graphite (TiC4), which is independent of the temperature. The reduction is explainable by the preferential erosion of carbon, resulting in a surface enrichment of the dopant and morphology changes [19]. Although the initial surface concentration of the dopant was lowered by the depletion of the carbide grains due to the polishing $[19,28]$, the thickness of the eroded carbon layer already exceeds the depletion zone for the highest fluence. This fact was proven by ion-beam analysis of the eroded surfaces.

To achieve the same reduction in the erosion yield for materials with a lower dopant concentration, e.g. 2 at. \% Ti (TiC2, Fig. 1), higher fluences have to be accumulated. A larger grain size, i.e. a larger main distance between individual grains, also leads to an increase of the necessary fluence to reduce the erosion. This was demonstrated with the coarser 10 at. \% Ti-doped material (LT10, Table I). The observed fluence dependence of the total erosion yield for this material is comparable to the fluence dependence of TiC2 (Fig. 1) [36].

Figure 2 shows the evolution of the erosion yield with the fluence for different pure and doped carbon materials, including TiC4, obtained by RF plasma exposure with $30 \mathrm{eV} \mathrm{D}$ ion impact. The most pronounced fluence dependence by plasma exposure was measured for a W-doped graphite (WC4in), which has a strongly inhomogeneous dopant distribution. The evolution of the erosion yield is comparable to those by the ion beam. But the absolute calibration of the erosion yield by weight loss 
seems to be not possible for this material because the weight loss data are too high and the spreading is too strong for the four specimens. The most reasonable explanation is that material was lost, i.e. carbide grains dropped off after exposure. So, the spectroscopically determined fluence dependence was scaled to an estimated total yield $Y_{\mathrm{t}+\mathrm{e}}$ of $0.75 \%$ in Fig. 2 .

For the RGTi91, only a slow but steady reduction is observed, which is expected because of the low dopant concentration and the large grain size of that material (Table I). The erosion yield of the $\mathrm{C} / \mathrm{SiC}$ (Table I) composite changes with fluence from a faster decrease to a slower one at high fluences $\left(\sim 5 \times 10^{25} \mathrm{D} / \mathrm{m}^{2}\right)$.

The erosion of TiC4 already reached steady state after a fluence of $\sim 3 \times 10^{25} \mathrm{D} / \mathrm{m}^{2}$. The carbon erosion necessary to create the dopant enrichment and the rough surface (see Section 3.3) seems to have already taken place in the stabilisation phase of the plasma. This implies that the fluence during the stabilisation phase was higher than calculated, which is also indicated by the spectroscopic data. Therefore, the yield is overestimated for that exposure. Additionally, the fact that this material was eroded by the plasma at an ion energy of $15 \mathrm{eV}$ instead of $30 \mathrm{eV}$ have to be taken into account. It is observed that the erosion yield of pure graphite for $30 \mathrm{eV}$ is increased by a factor of 1.5-2 compared with $15 \mathrm{eV}$ D $[31,32]$. The data for $15 \mathrm{eV}$ impact are also plotted with re-scaled fluence in Fig. 2 (factor 1.5).

For comparing the fluence dependencies by ion beam bombardment and plasma exposure, the fluence and the erosion yield axes of the ion beam data have to be adapted. The contribution of the thermal D to the erosion of TiC4 is equal to the contribution by $30 \mathrm{eV} \mathrm{D}$ only. Therefore, the
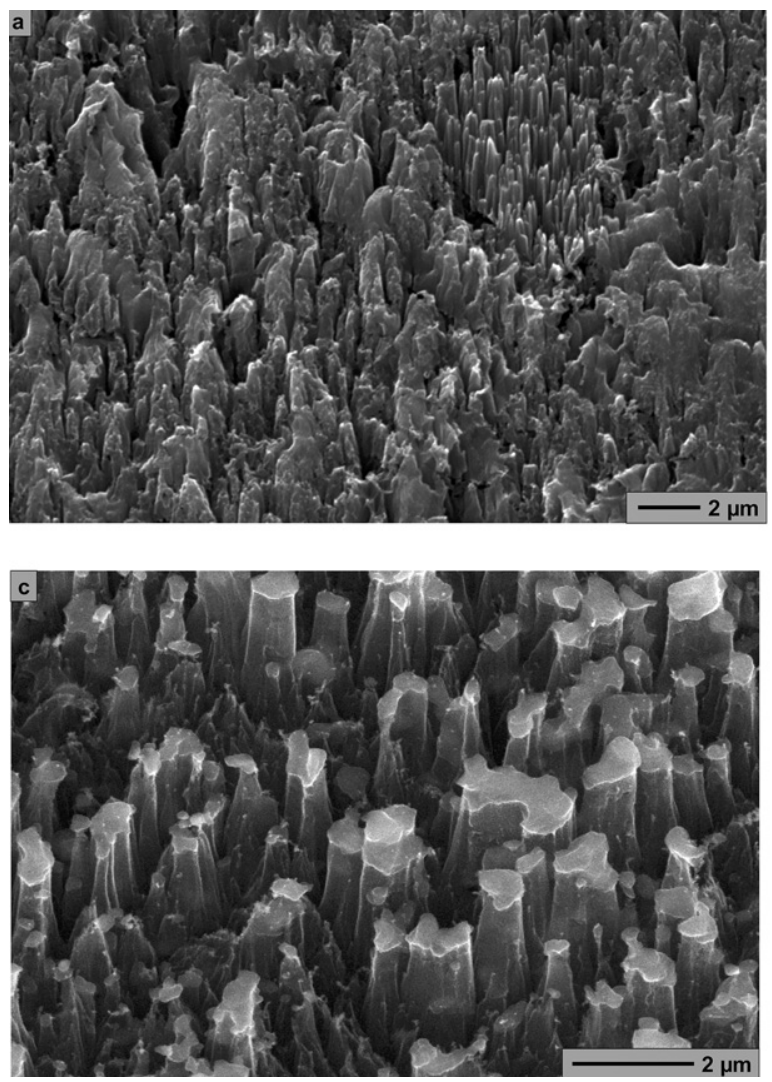

fluence scale of energetic D has to be compressed by a factor of 2, while the ion beam yield axis has to be stretched by a factor of 2 . The ion beam data of $\mathrm{TiC} 4$ are plotted with such an adaptation in Fig. 2. Even if for the plasmaexposed case only the steady state and not the decrease of the yield is observed, the results are in reasonable agreement with the ion beam results.

So, altogether the erosion yields for several materials measured by ion beams and plasma exposure are of the same order of magnitude and have the same evolution with fluence.

\subsection{Morphology of the eroded surfaces}

Figure 3 shows examples of the surface morphology created on pure and doped graphites after fluences of several $10^{25} \mathrm{D} / \mathrm{m}^{2}$ from ion beam and plasma exposure. Even on pure graphite, a very rough morphology is created by the incident D (Fig. 3(a), (b)). The graphitic areas (also between the dopant grains; Fig. 3(c), (d)) are covered with a needle-like structure after ion beam bombardment. The directional impact of the energetic $\mathrm{D}$ is evident from the images. The structure is more cotton-like and porous after plasma exposure. The thermal D from the plasma exposure slightly smears out the directional structure.

The influence of the dopant grains on the surface morphology is the formation of needles with dopant grains on top with only a slight undercut in the case of ion beam experiments (Fig. 3(c)), emphasising the directional impact. After plasma exposure, the surface is also strongly enriched with dopant grains, but additionally the dopant grains are strongly undercut (Fig. 3(d)). Some of the grains seem to have nearly no contact to the region below the grains. The
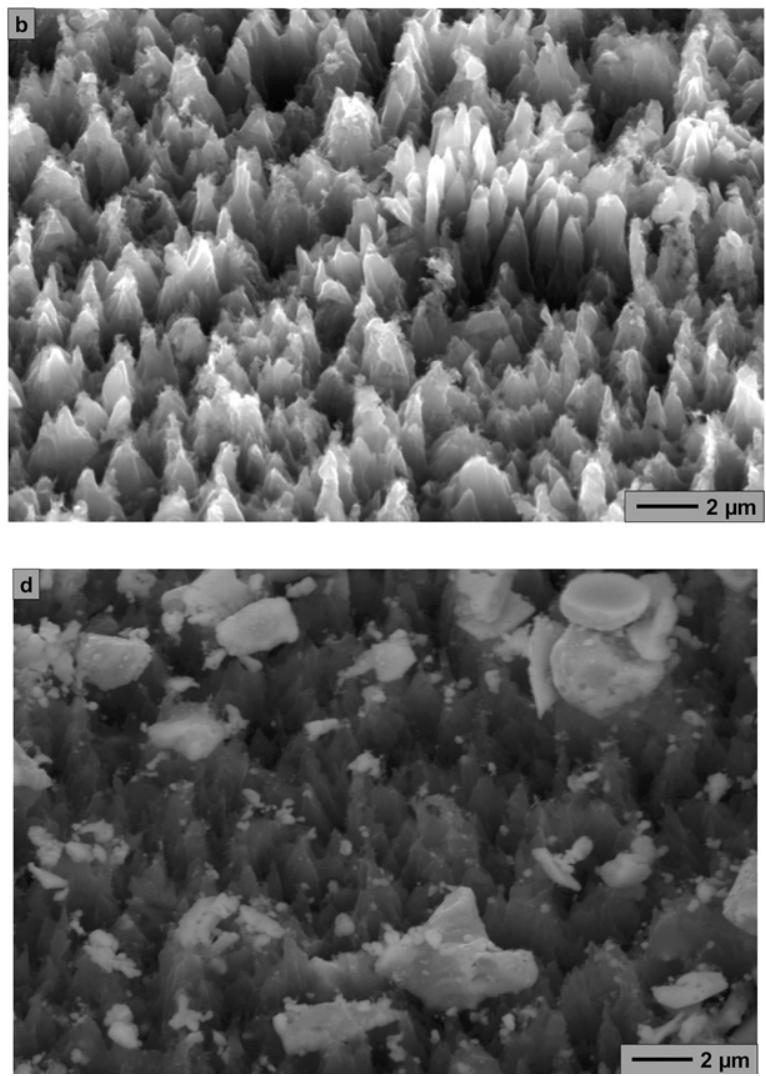

Fig. 3. Scanning electron microscopy images of the eroded surface: (a) pure graphite $\mathrm{C}_{\mathrm{CEIT}}$ after $1.0 \times 10^{25} \mathrm{D} / \mathrm{m}^{2} 30 \mathrm{eV}$ ion beam impact at $300 \mathrm{~K}$, (b) pure graphite $\mathrm{C}_{\mathrm{CEIT}}$ after $6.8 \times 10^{25} \mathrm{D} / \mathrm{m}^{2}$ plasma exposure with $30 \mathrm{eV} \mathrm{D}$ at $500 \mathrm{~K}$, (c) 2 at. $\%$ Ti-doped graphite TiC2 after $2.6 \times 10^{25} \mathrm{D} / \mathrm{m}^{2} 30 \mathrm{eV}$ ion beam impact at $300 \mathrm{~K}$, (d) 4 at. $\% \mathrm{Zr}$-doped graphite $\mathrm{ZrC} 4$ after $6.8 \times 10^{25} \mathrm{D} / \mathrm{m}^{2}$ plasma exposure with $30 \mathrm{eV} \mathrm{D}$ at $500 \mathrm{~K}$. 
shielding of the graphite beneath the dopant grains is not as efficient as for pure energetic D impact, perhaps due to the erosion by the thermal D. This difference in the undercut could be explained by erosion due to synergetic effects and a possible disturbance of the electrical potential on the microscopic scale.

The very rough surface of the pure graphites does not cause an observable fluence dependence of the erosion yield (see Section 3.1).

\section{Conclusion and summary}

Pure and carbide-doped graphites were eroded by monoenergetic and mass-separated hydrogen ion beams and by hydrogen containing planar inductively coupled RF plasmas. The main differences between the RF plasma exposure and the ion beam experiments are the flux ratio of thermal $(650 \mathrm{~K})$ to energetic $\mathrm{D}(30 \mathrm{eV})$ and the total $\mathrm{D}$ fluxes. With the plasma, high fluences $\left(>10^{22} \mathrm{D} / \mathrm{m}^{2}\right)$ can easily be achieved and a stable surface morphology under irradiation is accessible. The flux ratio between thermal and energetic $\mathrm{D}$ from the plasma was $\sim 5$ and the impacting D flux was $\sim 3.1 \times 10^{21} \mathrm{~m}^{-2} \mathrm{~s}^{-1}$.

For pure graphites the erosion yield is independent of the fluence although the surface is strongly roughened during the plasma exposure. Thermal atomic D impact alone results in a very small erosion yield [4]. The erosion yield by thermal + energetic D impact, i.e. the synergetic effect, depends on the graphitic structure, whereby the increase of the erosion yield compared to the ion beam data is less than a factor of 2 .

For the doped graphites, the reduction of the erosion yield is strongly correlated with the enrichment of dopant grains on the surface. A reduction by a factor of about 10 was achieved. Preferential erosion leads to a very rough surface morphology. The morphology resulting from the ion beam experiments consists of carbon needles with dopant grains on top, which have only a slight undercut. This undercut is stronger in the case of plasma exposure due to the synergetic contribution of the thermal $\mathrm{D}$ to the erosion.

The erosion yields for several materials gained by ion beams and plasma exposure are of the same order of magnitude and have the same evolution with fluence.

\section{Acknowledgement}

We would like to thank Dr. García-Rosales (CEIT and TECNUN, Campus Tecnológico, Universidad de Navarra, San Sebastián, Spain), Dr. Mühlratzer (MAN Technologie AG, Germany), and Dr. Burtseva (Efremov Institute, St. Petersburg, Russia) for providing materials for the experiments.

\section{References}

1. Janeschitz, G., ITER JCT and ITER HTs, J. Nucl. Mater. 290-293, 1 (2001).

2. Aymar, R. and International Team, J. Nucl. Mater. 307-311, 1 (2002).

3. Balden, M. and Roth, J., J. Nucl. Mater. 280, 39 (1999).

4. Vietzke, E. and Haasz, A. A., in: "Physical Processes of the Interaction of Fusion Plasmas with Solids", (Edited by W. O. Hofer and J. Roth) (Academic Press, San Diego 1996), p. 135.

5. Roth, J., Vietzke, E. and Haasz, A. A., Suppl. Nucl. Fusion 1, 63 (1991).

6. Haasz, A. A. et al., (Eds.), "Particle Induced Erosion of Be, C and W in Fusion Plasmas. Part A: Chemical Erosion of Carbon-Based Materials", Atomic and Plasma-Material Interaction Data for Fusion 7, part A, IAEA, Vienna (2001).

7. Eckstein, W. et al., (Eds.), "Particle Induced Erosion of Be, C and W in Fusion Plasmas. Part B: Physical Sputtering and RadiationEnhanced Sublimation", Atomic and Plasma-Material Interaction Data for Fusion 7, part B, IAEA, Vienna (2001).

8. Eckstein, W., García-Rosales, C., Roth, J. and Ottenberger, W., "Sputtering Data", (Max-Planck-Institut für Plasmaphysik, Garching, 1993), Vol 9/82.

9. Roth, J., J. Nucl. Mater. 266-269, 51 (1999).

10. Roth, J. and García-Rosales, C., Nucl. Fusion 36, 1647 (1996) and corrigendum Nucl. Fusion 37, 897 (1996).

11. Jacob, W., Thin Solid Films 326, 1 (1998).

12. Federici, G. et al., J. Nucl. Mater. 266-269, 14 (1999).

13. Brooks, J. N., Nucl. Technol. Fus. 4, 33 (1983).

14. Coster, D. P. et al., J. Nucl. Mater. 241-243, 690 (1997).

15. Federici, G. et al., J. Nucl. Mater. 290-293, 260 (1999).

16. Vietze, E., Flaskamp, K. and Philipps, V., J. Nucl. Mater. 111-112, 763 (1982).

17. Hopf, C., von Keudell, A. and Jacob, W., J. Appl. Phys. 94, 2373 (2003).

18. Balden, M., Physica Scripta T81, 64 (1999).

19. Balden, M. et al., J. Nucl. Mater. 290-293, 52 (2001).

20. García-Rosales, C., Roth, J. and Behrisch, R., J. Nucl. Mater. 212215, 1211 (1994).

21. Chen, A. Y. K., Haasz, A. A. and Davis, J. W., Nucl. Mater. 227, 66 (1995).

22. Plank, H., Schwörer, R. and Roth, J., Surf. Coat. Technol. 83, 93 (1996).

23. Yagi, H., Toyoda, H. and Sugai, H., J. Nucl. Mater. 313-316, 284 (2003).

24. Kornejew P., Bohmeyer, W., Reiner, H. D. and Wu, C. H., Physica Scripta T91, 29 (2001).

25. Butseva, T. et al., J. Nucl. Mater. 241, 716 (1997).

26. Phillips, V. et al., J. Nucl. Mater. 212-215, 1189 (1994).

27. De Juan Pardo, E., Balden, M., Cieciwa, B., García-Rosales, C. and Roth, J., Physica Scripta these proceedings.

28. Balden, M. et al., Physica Scripta T103, 38 (2003).

29. García-Rosales, C. et al., J. Nucl. Mater. 307-311, 1282 (2002).

30. Balden, M., Picarle, S. and Roth, J., J. Nucl. Mater. 290-293, 47 (2001).

31. Paulin, H., Ph.D. Thesis, University Augsburg, Germany, (2000).

32. Fantz, U. and Paulin, H., Physica Scripta T91, 25 (2001).

33. Starke, P. et al., to be published

34. Küppers, J., Surf. Sci. Reports 22, 249 (1995).

35. Mech, B. V., Haasz, A. A. and Davis, J. W., J. Nucl. Mater. 255, 153 (1998).

36. Balden, M. et al., unpublished data. 